\title{
Emergy-based sustainability assessment of different energy options for green buildings
}

Article

Accepted Version

Luo, Z., Zhao, J., Yao, R. and Shu, Z. (2015) Emergy-based sustainability assessment of different energy options for green buildings. Energy Conversion and Management, 100. pp. 97102. ISSN 0196-8904 doi:

https://doi.org/10.1016/j.enconman.2015.04.072 Available at https://centaur.reading.ac.uk/40133/

It is advisable to refer to the publisher's version if you intend to cite from the work. See Guidance on citing.

To link to this article DOI: http://dx.doi.org/10.1016/j.enconman.2015.04.072

Publisher: Elsevier

All outputs in CentAUR are protected by Intellectual Property Rights law, including copyright law. Copyright and IPR is retained by the creators or other copyright holders. Terms and conditions for use of this material are defined in the End User Agreement.

www.reading.ac.uk/centaur 
Central Archive at the University of Reading

Reading's research outputs online 


\section{Emergy-based sustainability assessment of different energy options for green buildings}

1. Key Laboratory of the Three Gorges Reservoir Region's Eco-Environment, Ministry of Education, Chongqing University, Chongqing, China

2. School of Construction Management and Engineering, University of Reading, Whiteknight campus, Reading, Berkshire, United Kingdom

3. School of Municipal Environmental Engineering, Harbin Institute of Technology, Harbin, China

4. Electro-Mechanical Engineering Group, Faculty of Engineering and The Environment, University of Southampton, United Kingdom

Word count of abstract: 296

Word count of text: 3448

\section{*Correspondence author:}

Dr. Zhiwen Luo, School of Construction Management and Engineering, Reading, United Kingdom 


\section{Abstract}

It is necessary to minimize the environmental impact and utilize natural resources in a sustainable and efficient manner in the early design stage of developing an environmentally-conscious design for a heating, ventilating and air-conditioning system. Energy supply options play a significant role in the total environmental load of heating, ventilating and air-conditioning systems. To assess the environmental impact of different energy options, a new method based on Emergy Analysis is proposed. Emergy Accounting, was first developed and widely used in the area of ecological engineering, but this is the first time it has been used in building service engineering. The environmental impacts due to the energy options are divided into four categories under the Emergy Framework: the depletion of natural resources, the greenhouse effect (carbon dioxide equivalents), the chemical rain effect (sulphur dioxide equivalents), and anthropogenic heat release. The depletion of non-renewable natural resources is indicated by the Environmental Load Ratio, and the environmental carrying capacity is developed to represent the environmental service to dilute the pollutants and anthropogenic heat released. This Emergy evaluation method provides a new way to integrate different environmental impacts under the same framework and thus facilitates better system choices. A case study of six different kinds of energy options consisting of renewable and non-renewable energy was performed by using Emergy Theory, and thus their relative environmental impacts were compared. The results show that the method of electricity generation in energy sources, especially for electricity-powered systems, is the most important factor to determine their overall environmental performance. The direct-fired lithium-bromide absorption type consumes more non-renewable energy, and contributes more to the urban heat island effect compared with other options having the same electricity supply. Using Emergy Analysis, designers and clients can make better-informed, environmentally-conscious selections of heating, ventilating and air-conditioning systems.

Keywords: Emergy, heating ventilating and air-conditioning, environmental impact assessment, renewable energy, anthropogenic heat 
Buildings contribute to about $40 \%$ of primary energy consumption in developed countries, and the heating, ventilating and air-conditioning (HVAC) system constitutes approximately $50-60 \%$ of the annual energy consumption in residential buildings [1]. In China, the proportion of national energy consumption from building sector was around 30\% in 2008 [2]. But in some specific cities such as Chongqing and Shanghai, central air-conditioning alone consumes around $23 \%$ and $31.1 \%$ of their total energy consumption, respectively [3]. With China's rapid urbanization, such proportions are likely to increase [4]. The ever-increasing energy consumption from the buildings inevitably introduces enormous negative environmental consequences such as greenhouse gas (GHG) emissions and the release of various pollutants and wastes. For example, a study in Finland indicated that energy used in the operation process of HVAC systems and in electricity generation contributes to $80-90 \%$ of climate change and acidification impacts from buildings [5]. Assessments of the environmental impact of buildings which can support environmental decision-making are therefore the focus of many studies. BEAM-Plus in Hong Kong, and GB/T in China. The other type is the analysis-oriented approach, which involves quantitatively-based research on specific indicators or aspects, and normally serves as the technical support to the application-oriented method. The analysis-oriented approach includes several elaborative techniques such as life cycle assessment (LCA), embodied 
quantifies the environmental impacts related to the entire life cycle of a product or process in respect of the energy and material flow [7]. Blom et al. [8,9] studied different types of heating and ventilation systems in Dutch dwellings using LCA-based environmental assessment, and found that although heat pumps were considered to be a more sustainable technology, they had more negative environmental impacts compared with gas-fired boilers because they use extra electricity and more material resources. The embodied energy analysis method specifically investigates the energy efficiency of all the gross commercial energy (only including fossil energy such as coal, oil and gas) [10]. Based on the second law of thermodynamics, exergy can identify the imperfection of the system as well as the locations of the exergy losses. Yang et al. [11] compared the environmental impacts of two residential heating systems during the life cycle span using expanded cumulative exergy consumption (ECExC) as the indicator. The most significant environmental impacts were identified during the operating phase, and it was found that the forced-air heating system had a lower life-cycle cost than the hot water heating system. Despite the popularity of the above-mentioned indicators, current methodologies to quantitatively assess a building's environmental impact have the following shortcomings:

1) The above-mentioned indicators ignore the critical role that nature's products and services play in supporting industrial activities. For example, exergy analysis as a thermodynamic approach has been extended for life cycle and sustainability assessment; it takes for granted all goods and services from ecosystems which are required in sustaining all industrial activities [12]. There is no inclusion of the energy being used by ecosystems or ecological goods that indirectly contribute to building life cycle energy use. Environmental services such as the wind and solar energy are thought to be naturally free, but they should have an energy value [13].

2) There is a lack of holistic evaluation of the overall environmental impact. It is a challenging task to create a unified framework where different environmental impacts can be compared and synthesized. Biophysical/thermodynamic models (exergy, embodied energy etc.) allow substitution within the same form of natural capital and resource but not between 
different kinds or qualities [13]. In addition, in a building system, apart from the energy and material flows, there are the flows in relation to economic and social activities which are hard to define using the above-mentioned indicators.

3) No studies have considered the assessment of anthropogenic heat emission into the atmosphere by the HVAC system, which is regarded as one of the dominating factors for controlling urban heat islands [14].

In order to address these above-mentioned concerns, the concept of 'Emergy' (spelled with an ' $m$ ') is introduced in the present study. Emergy Analysis (EA) is a thermodynamic environmental accounting method based on all forms of energy, materials, human labor, economic services, and information, which was first presented by Odum in the 1980s [15]. All types of resources can be converted into equivalents of one form of energy, i.e. solar energy, which is the common basis of all energy flows circulating within the biosphere. The ecological cost from the environmental service, which is difficult to value using commonly-defined, energy-based indicators, can be assessed by Emergy Accounting to unveil the real sustainability of the whole system. The more work done to produce a product or make a service, the higher the Emergy content of the product or service would be. EA has been widely applied in ecological engineering. Only a handful of research efforts have been made to assess building systems under the emergy framework. Meillaud, et al. [16] was the first to apply emergy accounting into building sector, and they evaluated a school building in Switzerland, with the output of scientific information disseminated via publications, courses, students, and services. Pulselli et al [17] evaluated the environmental resource use of three wall systems for building envelops relative to different geographical locations and climates using emergy evaluation. Pulselli et al [18] applied emergy analysis to assess the specific emergy of cement and concrete for building materials. The results identified a high dependence of cement and concrete production on external resource flows. Li et al. [19] presented an eco-efficiency evaluation of building manufacturing for six residential buildings in China using emergy analysis. The evaluation results revealed that construction materials were the dominating source of the total emergy amount for building manufacturing. Surprisingly, no studies of HVAC systems have been found, especially energy supply options. In this paper, the efforts are devoted to evaluating the environmental performance of 
the different energy options adopted in the HVAC system. In order to take into account the anthropogenic heat emissions from the HVAC system, the concept of a support area to absorb anthropogenic heat emission based on emergy analysis was developed. The emergy evaluation considers the environmental impact of natural resources depletion, GHG emission and anthropogenic heat within the same framework. Therefore, the environmentally favorable design solutions can be optimized. This emergy-based framework can aid decision-making in the selection of the best available technologies to minimize the environmental impact of different energy options for HVAC systems.

\section{Environmental impact assessment indicators based on Emergy}

\subsection{Emergy concept}

By definition, emergy uses the thermodynamic basis of all forms of energy and materials (measured by their heat content, mass or energy, i.e. the available energy of each flow relative to the environment), but converts them into equivalents of one form of energy, usually sunlight. The units of emergy are emjoules, to distinguish them from joules, referring to the available energy of one kind consumed in transformations. For example, sunlight, fuel, electricity, and human services can be put on a common basis by expressing them all as the emjoules of solar energy required to produce each one. Therefore, solar emergy is often used with unit solar emjoules (abbreviation: sej). As a whole, the emergy analysis accounts for quality differences among distinct forms of energy and allows for the inclusion of information and monetary flows with energy and materials [20].

Emergy evaluation methods have been detailed in a spectrum of publications. For the reader's convenience, some essential concepts related to emergy are listed below:

- Empower $\left(J_{\mathrm{ems}}\right)$ is the emergy flow per unit time (units: solar emjoules per year sej/yr);

- Transformity $\left(T_{\mathrm{rs}}\right)$ is the emergy per unit available energy. Example: solar transformity in solar emjoules per joule (abbreviation: sej/J). Transformity is the intensive unit of emergy and measures the quality of energy. The higher the transformity, the higher that 
- Specified Emergy $\left(T_{\mathrm{m}}\right)$ is emergy per unit mass, which is useful where data are in mass units. It is usually expressed as solar emergy per gram (sej/g).

- Emergy money ratio $(\mathrm{Ems} / \$)$ is a measure of the real wealth buying power of money calculated for a state or nation in a given year. The emergy money ratio is found by dividing the total emergy use of a nation by its gross domestic product (GDP). Thus it varies by counties. It is useful where data on human services are in money units.

Emergy analysis looks into different flows including energy, materials, service, and even information and puts them into a common framework, just like a bridge to create the communications between the different aspects. The emergy of a product can be obtained by multiplying a quantity of available energy by its transformity.

\subsection{Emergy-based environmental impact indicator}

Some researchers have done a lot of original work to develop various indices to assess the sustainability of the system or products based on the emergy concept. Odum [21] proposed the concept of the Environmental Load Ratio $(E L R)$, defined as the overall non-renewable resource input dividing the renewable resource input in the system or product studied.

$$
E L R=(F+N) / R
$$

Where $F$ is the total emergy value of the products and service input in the system, $N$ is the total emergy value of the non-renewable resource and $R$ is the total emergy value of the renewable resource. ELR highlights the utilization of renewable resources in the product, service, or system. The higher the ELR value is, the lower the degree of renewable resource that will be used. However, this fails to consider the influence of the waste gas emissions to the surrounding environment. In 2002, Ulgiati and Brown [20] regarded the environment as the supporting sink to absorb or dispose of the waste by-products and proposed the index of support area to quantify the environmental capacity to drive the dilution process. The calculation procedure is defined as follows: 
1) Calculate or measure to determine the amount of released chemicals, $W$, in $\mathrm{kg}$ or g;

2) Calculate the volume or mass of the air required $(M)$ to dilute these emissions to one of two concentration levels: acceptable concentration or background concentration. The lower the concentration threshold is, the higher the dilution mass required.

$$
M=d \times W / c
$$

where $M$ is the mass of dilution air, $d$ is the air density, $W$ is the amount of emission of a given chemical from the system or product, and $c$ is the acceptable concentration or background concentration of this chemical.

3) Determine the required emergy value of the environmental service for diluting the waste by calculating the kinetic energy of the dilution air, as shown in Eq.(3).

$$
R_{s}=\frac{1}{2} M v^{2} T_{r}
$$

where $v$ is the mean air speed in the area and $T_{\mathrm{r}}$ is the transformity of the wind energy. This is a measure of the wind energy needed to disperse and dilute the pollutants.

4) Calculate the support area $A_{\mathrm{s}}$ according to Eq.(4).

$$
A_{s}=R_{s} / R_{0}
$$

where $R_{0}$ is the wind energy flow per unit area in the region. The larger the support area is, the greater the environmental services that should be accounted for in diluting the pollutants. Thus, the support area in a defined region can be used to evaluate the environmental impact of the waste emissions of a certain operating system or product.

For the energy supply (either heating or cooling) of an HVAC system, the environmental impacts can be assigned to four categories: depletion of the natural resources, the greenhouse effect $\left(\mathrm{CO}_{2}\right.$ equivalents), the chemical rain effect ( $\mathrm{SO}_{2}$ equivalents) and anthropogenic heat release [10]. Based on the analysis of the two indices above, it is reasonable to assess the environmental impact of the depletion of natural resources with the ELR index while using the environmental 
capacity concept for the greenhouse and chemical rain effects. The question is how to quantify

212 the environmental impact caused by anthropogenic heat emissions during the life cycle of the

213 energy supply options. To address this, we adopt the same idea as the one applied to the pollutant

214 emission. We consider the ambient air as the heat sink with the capacity to absorb and dilute the

215 released heat. Accordingly, we derive Eq. (5) as follows:

$$
M=\frac{Q}{C_{p}\left(t_{p}-t_{0}\right)}
$$

where $Q$ is the released heat, $M$ is the mass of air required to change the background temperature $t_{0}$ to the threshold temperature $t_{\mathrm{p}}$ in which people can still live, and $C_{\mathrm{p}}$ is the heat capacity of the air. In the same manner as pollution dilution, the carrying capacity for diluting the heat emission by environmental service can be expressed by the support area, as in Eq. (3-4).

\section{Case study: results and discussions}

To study the environmental impact of the sources supplying energy for the HVAC system, a six-story office building located in Xi'an, China, is selected as a case study. The building height is $18 \mathrm{~m}$ and the total floor area is $14,700 \mathrm{~m}^{2}$. Xi'an is located in northwest China, characterized by a temperate, semiarid climate. It requires cooling in summer and heating in winter. Six types of system supplying heating and cooling are chosen (see Table 1). Option A is a system with a water chiller for cooling in summer and a gas boiler for heating in winter. Option B is a direct-fired Li-Br absorption-type refrigeration and heating system and Option $\mathrm{C}$ is an air-source heat pump system. The electricity supplied for Options A-C is produced from a coal thermal plant. Options D-F are the same as Options A-C except for the electricity supply coming from hydraulic power. The other parts of the HVAC system remain the same for all the options. The office building is occupied from 8:00 to 18:00h.

The annual energy consumption was obtained by the BIN method [22] which simulates the energy 
consumption at different outdoor dry-bulb temperatures and the individual results are multiplied by the number of hours $N_{\text {bin }}$ in the temperature interval (bin) centered around that temperature.

$$
Q_{\text {bin }}=N_{\text {bin }} \frac{K_{\text {tot }}}{\eta_{\mathrm{h}}}\left|t_{\text {bal }}-t_{o}\right|
$$

Where $\mathrm{K}_{\text {tot }}$ is the total heat transfer coefficient; $\eta_{h}$ is the efficiency of the HVAC system; $t_{b a l}$ is the balance-point temperature; and $t_{o}$ is the outdoor dry-bulb temperature. Two steps are required to calculate the annual energy consumption based on the Bin method [23]: 1) calculate the bin weather data based on a typical meteorological year (TMY) data; 2) calculate the building energy consumption using Eq. (6) in each bin, and the total energy consumption is the sum over all defined bins. The bin data for the city of Xi'an was derived from [24]. The detailed calculation can be found in [25] and the simulation results are summarized in Table 2. This shows that Options $\mathrm{C}$ and $\mathrm{F}$ use the largest amount of electricity and Options B and E exhibit the highest annual gas consumption during the operation stage.

When applying emergy analysis, the emergy flow diagram for the heating and cooling sources can be drawn as in Figure 1. It shows the renewable and non-renewable input for the system as well as the purchased inputs from the economic system. The environmental service system for diluting the pollutants and the heat sink are also shown. Table 3 gives a detailed emergy accounting for Option A during its life cycle. For the construction phase, the emergy value is obtained using the emergy money ratio multiplied by the equipment purchase value as the detailed material flow is not available.

Conversion factors and the reference studies from which they have been extracted are clearly listed in each table. The same procedure is used for the other types investigated (B-F) and details are available on request. It is clearly shown that the total emergy (converted to solar emergy) in the operation 
phase is dominant in the entire life cycle of the system, one order of magnitude higher than the construction phase, which agrees with the previous work on exergy evaluation in [11]. Therefore the renewable input into the system will be mainly determined by the system for electricity generation and supply.

Based on the emergy accounting information, the related environmental indictor in terms of renewable energy utilization, $E L R$, can be obtained, as shown in Fig. 2. It can be seen that Option $\mathrm{F}$ has the best utilization of renewable energy, because most of the energy consumed in F comes from the electricity which is produced mainly by renewable hydraulic power. This makes the best use of renewable water resources. Meanwhile, Option B exhibits the highest value of ELR (as high as $\sim 70$ ) although it emits relatively fewer pollutants, because the natural gas is non-renewable. This value is much higher than that in fossil fuel plants [26] (11.4 for coal and 14.2 for oil), as plenty of natural gas is also consumed in Option B except for the electricity from the coal thermal plant. It is also interesting to notice that Option C has a lower value of ELR compared with Option E, although the electricity used in Option $C$ is provided by a coal thermal plant. This study confirms the importance of including the method of electricity generation in the environmental impact analysis. A similar conclusion has been drawn by [27].

The pollutants released during the whole life cycle of the system can be identified and categorized into two groups: the greenhouse effect and the chemical rain effect, represented by $\mathrm{CO}_{2}$ and $\mathrm{SO}_{2}$ equivalents, respectively. Table 4 presents the calculated $\mathrm{CO}_{2}$ and $\mathrm{SO}_{2}$ equivalents as well as the amount of released anthropogenic heat for the different options. In order to calculate the carrying capacity for the environmental service to dilute the pollutants, it is a prerequisite to know the threshold or 
background value for each pollutant. The threshold concentration for $\mathrm{SO}_{2}$ is $0.15 \mathrm{mg} / \mathrm{m}^{3}$ according to [28] and the background concentration for $\mathrm{CO}_{2}$ is used as there is no such threshold value for $\mathrm{CO}_{2}$. The renewable emergy flow per unit area $\left(R_{0}\right)$ is taken as $1.83 \mathrm{E} 10 \mathrm{se} /\left(\mathrm{m}^{2}\right.$ year-1) by following [20]. Following Eqs. (2-4), the support area for the local atmospheric environmental service to dilute the pollutants can be obtained and shown in Table 5. It is evident that much smaller support areas are given to the options with renewable electricity input such as D, E, and F. The support areas for the systems using electricity from non-renewable resources are comparable with the previous results in [20] for fossil fuel power plants, which is $2.87 \mathrm{E} 6 \mathrm{~m}^{2}$. The relatively higher value may result from the additional usage of natural gas, which can also be responsible for the higher emission of pollutants. In a similar manner, the support area for the anthropogenic heat released can also be obtained and shown in Figure 3. The climate data, including average summer temperature and wind speed, are reconstructed from Typical Metrological Year (TMY) data. As depicted in Figure 3, the electricalpowered systems have comparable support areas for heat dilution as they have similar COP values. However, the Li-Br-absorption type chiller requires double the support area as the water chiller and heat pump types.

If all these indicators are taken into account, Option F (air-source heat pump with electricity from hydraulic power) yields the lowest environmental impact while Option B (direct-fired Li-Br absorption cooling and heating system with electricity from a coal thermal plant) is highest. That is because Option B consumes the most non-renewable resources whilst also emitting waste to the ambient environment. This suggests that for renewable electricity generation, the air-source heat pump system will possess the highest environmental merits. 


\section{Conclusions}

Emergy accounting has been used in this paper to evaluate the environmental impacts of different energy sources for HVAC systems. The environmental loading due to energy sources of a typical HVAC system is divided into four categories within the emergy framework: the depletion of the natural resources, the greenhouse effect $\left(\mathrm{CO}_{2}\right.$ equivalents), the chemical rain effect $\left(\mathrm{SO}_{2}\right.$ equivalents), and anthropogenic heat release. Different emergy-based indicators were proposed to assess different environmental impacts. The environmental load ratio (ELR) can be used to represent how much renewable energy is utilized and the environmental carrying capacity in terms of support area is adopted to evaluate the ability of the environmental service to dilute the pollutants. Especially for the anthropogenic heat released from the HVAC system, we developed a similar idea of carrying capacity to be used for the dilution of pollutants. Therefore, the support area for the heat sink to absorb the heat emitted can be calculated. To apply these new indicators into practice, a case study with six different types of energy options for the HVAC system in an office building in Xi'an, China, was carried out. The results show that the method of electricity generation for the energy sources, especially for electrical-powered systems, is the most important factor in determining the overall environmental performance. The direct-fired $\mathrm{Li}-\mathrm{Br}$ absorption type consumes more non-renewable energy, and contributes more to the urban heat island effect compared to other options for the same electricity supply.

\section{Acknowledgement}

The authors would like to express their gratitude for the financial support from the Key laboratory of the Three Gorges Reservoir Region's Eco-Environment, Ministry of Education, Chongqing University, China, and the Walker Institute Fund from the University of Reading, UK. The authors would also like 
to thank three anonymous reviewers for their helpful comments to further improve the quality of the paper.

\section{References}

[1] Pérez-Lombard, L., Ortiz, J., Pout, C., 2008. A review on buildings energy consumption information. Energy and Buildings 40, 394-398.

[2] Wan, K.K.W., Li, D.H.W., Liu, D., Lam, J.C., 2011. Future trends of building heating and cooling loads and energy consumption in different climates. Building and Environment 46, 223-234.

[3] Ministry of Construction. 2005. Report on "building survey for large-scale public buildings in Beijing, Shanghai, Shenzhen and Chongqing”. Beijing: Ministry of Construction [in Chinese]

[4] Li, B., Yao, R., 2009. Urbanisation and its impact on building energy consumption and efficiency in China. Renewable Energy 34, 1994-1998

[5] Sharma, A., Saxena, A., Sethi, M., Shree, V., Varun, 2011. Life cycle assessment of buildings: A review. Renewable and Sustainable Energy Reviews 15, 871-875.

[6] Liu, M., Li, B., Yao, R., 2010. A generic model of Exergy Assessment for the Environmental Impact of Building Lifecycle. Energy and Buildings 42, 1482-1490.

[7] Cabeza, L.F., Rincón, L., Vilariño, V., Pérez, G., Castell, A., 2014. Life cycle assessment (LCA) and life cycle energy analysis (LCEA) of buildings and the building sector: A review. Renewable and Sustainable Energy Reviews 29, 394-416.

[8] Blom, I., Itard, L., Meijer, A., 2010. LCA-based environmental assessment of the use and maintenance of heating and ventilation systems in Dutch dwellings. Building and Environment 45, 2362-2372.

[9] Blom, I., Itard, L., Meijer, A., 2011. Environmental impact of building-related and user-related energy consumption in dwellings. Building and Environment 46, 1657-1669.

[10] Abanda, F.H., Tah, J.H.M., Cheung, F.K.T., 2013. Mathematical modelling of embodied energy, greenhouse gases, waste, time-cost parameters of building projects: A review. Building and Environment 59, 23-37.

[11] Yang, L., Zmeureanu, R., Rivard, H., 2008. Comparison of environmental impacts of two residential heating systems. Building and Environment 43, 1072-1081.

[12] Hau, J.L., Bakshi, B.R., 2004. Expanding Exergy Analysis to Account for Ecosystem Products and Services. Environmental Science \& Technology 38, 3768-3777.

[13] Srinivasan, R.S., Ingwersen, W., Trucco, C., Ries, R., Campbell, D., 2014. Comparison of energybased indicators used in life cycle assessment tools for buildings. Building and Environment 79, 138151.

[14] Sailor, D., 2011. A review of methods for estimating anthropogenic heat and moisture emissions in the urban environment. International Journal of Climatology. 31,189-199

[15] Odum, H.T. System ecology. New York, USA: Wiley; 1983

[16] Meillaud, F., Gay, J.B., Brown, M.T., 2005. Evaluation of a building using the emergy method. Solar Energy 79, 204-212.

[17] Pulselli, R.M., Simoncini, E., Marchettini, N., 2009. Energy and emergy based cost-benefit evaluation of building envelopes relative to geographical location and climate. Building and Environment 44, 920-928. 
[18] Pulselli, R.M., Simoncini, E., Ridolfi, R., Bastianoni, S., 2008. Specific emergy of cement and concrete: An energy-based appraisal of building materials and their transport. Ecological Indicators 8 , 647-656.

[19] Li, D., Zhu, J, Hui, E., Leung, B., and Li, Q. 2011. An emergy analysis-based methodology for ecoefficiency evaluation of building manufactring. Ecological indicator 11, 1419-1425.

[20] Ulgiati, S., Brown, M.T., 2002. Quantifying the environmental support for dilution and abatement of process emissions: The case of electricity production. Journal of Cleaner Production 10, 335-348. [21] Odum, H.T., Odum, B., 2003. Concepts and methods of ecological engineering. Ecological Engineering 20, 339-361.

[22] ASHRAE handbook fundamentals. 2013. ASHRAE

[23] Wang, Z., Ding, Y., Geng, G., Zhu, N., 2014. Analysis of energy efficiency retrofit schemes for heating, ventilating and air-conditioning systems in existing office buildings based on the modified bin method. Energy Conversion and Management 77, 233-242

[24] Peng, Z., Jin, Z., Guoqiang, Z., Yezheng, W., 2009. Generation of ambient temperature bin data of 26 cities in China. Energy Conversion and Management 50, 543-553.

[25] Li, R., 2005. Analysis of energy consumption and life cycle assessment of environmental impact of air conditioning cold and heat source. Master thesis, Xi'an, Xi'an University of Arch \& Tech (In Chinese)

[26] Brown, M.T., Ulgiati, S., 2002. Emergy evaluations and environmental loading of electricity production systems. Journal of Cleaner Production 10, 321-334.

[27] Cheng, C., Zhang, Y., Ma, L., 2012. Assessment for central heating systems with different heat sources: A case study. Energy and Buildings 48, 168-174.

[28] Standard for Atmospheric Air Quality in China, GB3095-2010

[29] Dai, Y., 2004. Emergy evaluation of industry system. Master thesis, Xi'an, Xi'an Jiaotong University (In Chinese) 
Table 1: Different types of heat and cold sources.

\begin{tabular}{|c|l|l|}
\hline Options & \multicolumn{1}{|c|}{ Energy option } & \multicolumn{1}{c|}{ Description } \\
\hline A & Water chiller \& gas boiler* & $\begin{array}{l}\text { Chiller: Carrier 30HXC250A; Rated cooling } \\
\text { power:870 kW } \\
\text { Gas boiler: Huantong E125. Rated heating } \\
\text { power:1454kW } \\
\text { Cooling tower: Lingdian CT/CN250 }\end{array}$ \\
\hline B & $\begin{array}{l}\text { Direct-fired Li-Br absorption-type } \\
\text { refrigerating and heating system }\end{array}$ & $\begin{array}{l}\text { Carrier 16DN, 2 sets } \\
\text { Rated cooling power: 985 kW } \\
\text { Rated heating power: 826 kW } \\
\text { Cooling tower: Lingdian CT/CN250 }\end{array}$ \\
\hline C & Air-source heat pump* & $\begin{array}{l}\text { Carrier 30AQA 240, 3 sets } \\
\text { Rated cooling power: 680 kW } \\
\text { Rated heating power: 620 kW }\end{array}$ \\
\hline D & Water chiller \& gas boiler \# & Same as A \\
\hline E & $\begin{array}{l}\text { Direct-fired Li-Br absorption-type } \\
\text { refrigerating and heating system } \#\end{array}$ & Same as B \\
\hline F & Air-source heat pump\# & Same as C \\
\hline
\end{tabular}

* Electricity is generated by coal thermal plant; \# Electricity is generated by hydraulic power plant 
Table 2: Summary of annual energy consumption

\begin{tabular}{ccccc}
\hline & $\begin{array}{c}\text { Water } \\
\text { chiller +gas } \\
\text { boiler }\end{array}$ & $\begin{array}{c}\text { Direct-fired Li-Br } \\
\text { absorption-type } \\
\text { refrigerating and } \\
\text { heating system }\end{array}$ & $\begin{array}{c}\text { Air- } \\
\text { source } \\
\text { heat } \\
\text { pump }\end{array}$ \\
\hline $\begin{array}{c}\text { Energy consumption } \\
\text { of main part }\end{array}$ & $\begin{array}{c}\text { Electricity } \\
(\mathrm{kWh}) \\
\text { Gas }\left(\mathrm{Nm}^{3}\right)\end{array}$ & 190000 & 37623 & 539509 \\
$\begin{array}{c}\text { Electricity } \\
\text { Consumption of } \\
\text { cooling water } \\
\text { system }\end{array}$ & $\begin{array}{c}\text { (kWh) } \\
\text { Cooling pump } \\
(\mathrm{kWh})\end{array}$ & 11231 & 168579 & - \\
$\begin{array}{c}\text { Total electricity consumption }(\mathrm{kWh}) \\
\text { Total gas consumption }\left(\mathrm{Nm}^{3}\right)\end{array}$ & $\begin{array}{c}239008 \\
\text { (n) }\end{array}$ & 15315 & - \\
\hline
\end{tabular}


Table 3: Emergy inventory analysis of Option A in the life cycle period

\begin{tabular}{|c|c|c|c|c|c|c|}
\hline Item & Unit & $\mathrm{N}^{0}$ & Value & $\begin{array}{c}\text { Transformity } \\
\text { (sej/Unit) }\end{array}$ & Ref for transf & Solar emergy \\
\hline \multicolumn{7}{|c|}{ Construction phase (inputs are calculated on an annual basis, divided by life cycle $=15$ years) } \\
\hline Water chiller & $\begin{array}{c}10 \mathrm{~K} \\
¥\end{array}$ & 2 & 4.78 & $1.77 \mathrm{E}+15$ & [29] & $1.69 \mathrm{E}+16$ \\
\hline Cooling tower & $\begin{array}{l}10 \mathrm{~K} \\
¥\end{array}$ & 2 & 0.43 & $1.77 \mathrm{E}+15$ & [29] & $1.52 \mathrm{E}+15$ \\
\hline pump & $\begin{array}{c}10 \mathrm{~K} \\
Y\end{array}$ & 3 & 0.05 & $1.77 \mathrm{E}+15$ & [29] & $2.66 \mathrm{E}+14$ \\
\hline $\begin{array}{l}\text { Water-water heat } \\
\text { exchanger }\end{array}$ & $\begin{array}{c}10 \mathrm{~K} \\
¥\end{array}$ & 1 & 1 & $1.77 \mathrm{E}+15$ & [29] & $1.77 \mathrm{E}+15$ \\
\hline Gas boiler & $\begin{array}{c}10 \mathrm{~K} \\
Y\end{array}$ & 1 & 1.87 & $1.77 \mathrm{E}+15$ & [29] & $3.31 \mathrm{E}+15$ \\
\hline $\begin{array}{l}\text { Assembling } \\
\text { service }\end{array}$ & $\begin{array}{c}10 \mathrm{~K} \\
¥\end{array}$ & & 0.08 & $1.77 \mathrm{E}+15$ & [29] & $1.42 \mathrm{E}+14$ \\
\hline Total & & & & & & $2.39 \mathrm{E}+16$ \\
\hline \multicolumn{7}{|c|}{ Operating phase } \\
\hline Electricity & $\mathrm{J}$ & & $8.6 \mathrm{E}+11$ & $1.71 \mathrm{E}+05$ & {$[20]$} & $1.47 \mathrm{E}+17^{*}$ \\
\hline Gas & $\mathrm{J}$ & & $4.16 \mathrm{E}+12$ & $4.80 \mathrm{E}+04$ & {$[20]$} & $1.99 \mathrm{E}+17$ \\
\hline Operation service & $\begin{array}{c}10 \mathrm{~K} \\
¥\end{array}$ & & 3.43 & $1.77 \mathrm{E}+15$ & [29] & $4.04 \mathrm{E}+15$ \\
\hline Total & & & & & & $3.53 \mathrm{E}+17$ \\
\hline
\end{tabular}

Notice: Renewable energy presents $8.79 \%$ of the total energy in coal thermal [20] 
Table 4: Summary of pollutant and anthropogenic heat emissions for different types of options

\begin{tabular}{cccc}
\hline & $\begin{array}{c}\text { GHG effect } \\
\left(\mathrm{kg} \mathrm{CO}_{2} \text { eq/a }\right)\end{array}$ & $\begin{array}{c}\text { Chemical rain effect } \\
\left(\mathrm{kg} \mathrm{SO}_{2} \text { eq/a }\right)\end{array}$ & $\begin{array}{c}\text { Anthropogenic } \\
\text { heat }(\mathrm{MJ} / \mathrm{a})\end{array}$ \\
\hline $\mathrm{A}$ & 258494912 & 3337727.6 & 4234320 \\
$\mathrm{~B}$ & 123655913 & 1595070.6 & 7341840 \\
$\mathrm{C}$ & 583253460 & 7533648.2 & 4673956 \\
$\mathrm{D}$ & 105756 & 198.2 & 4234320 \\
$\mathrm{E}$ & 197596 & 410.5 & 7341840 \\
$\mathrm{~F}$ & 0 & 0 & 4673956 \\
\hline
\end{tabular}


Table 5: Range of support areas for different types of options

\begin{tabular}{crr}
\hline & $\begin{array}{c}\text { GHG effect } \mathrm{CO}_{2} \text { eq/a } \\
\left(\mathrm{m}^{2}\right)\end{array}$ & $\begin{array}{c}\text { Chemical rain effect- } \\
\mathrm{SO}_{2} \text { eq/a } \\
\left(\mathrm{m}^{2}\right)\end{array}$ \\
\hline $\mathrm{A}$ & $6.34 \mathrm{E}+04$ & $3.55 \mathrm{E}+06$ \\
$\mathrm{~B}$ & $3.04 \mathrm{E}+04$ & $1.69 \mathrm{E}+06$ \\
$\mathrm{C}$ & $1.43 \mathrm{E}+05$ & $7.98 \mathrm{E}+06$ \\
$\mathrm{D}$ & $2.60 \mathrm{E}+01$ & $2.10 \mathrm{E}+02$ \\
$\mathrm{E}$ & $4.86 \mathrm{E}+01$ & $4.36 \mathrm{E}+02$ \\
$\mathrm{~F}$ & $0.00 \mathrm{E}+00$ & $0.00 \mathrm{E}+00$ \\
\hline
\end{tabular}




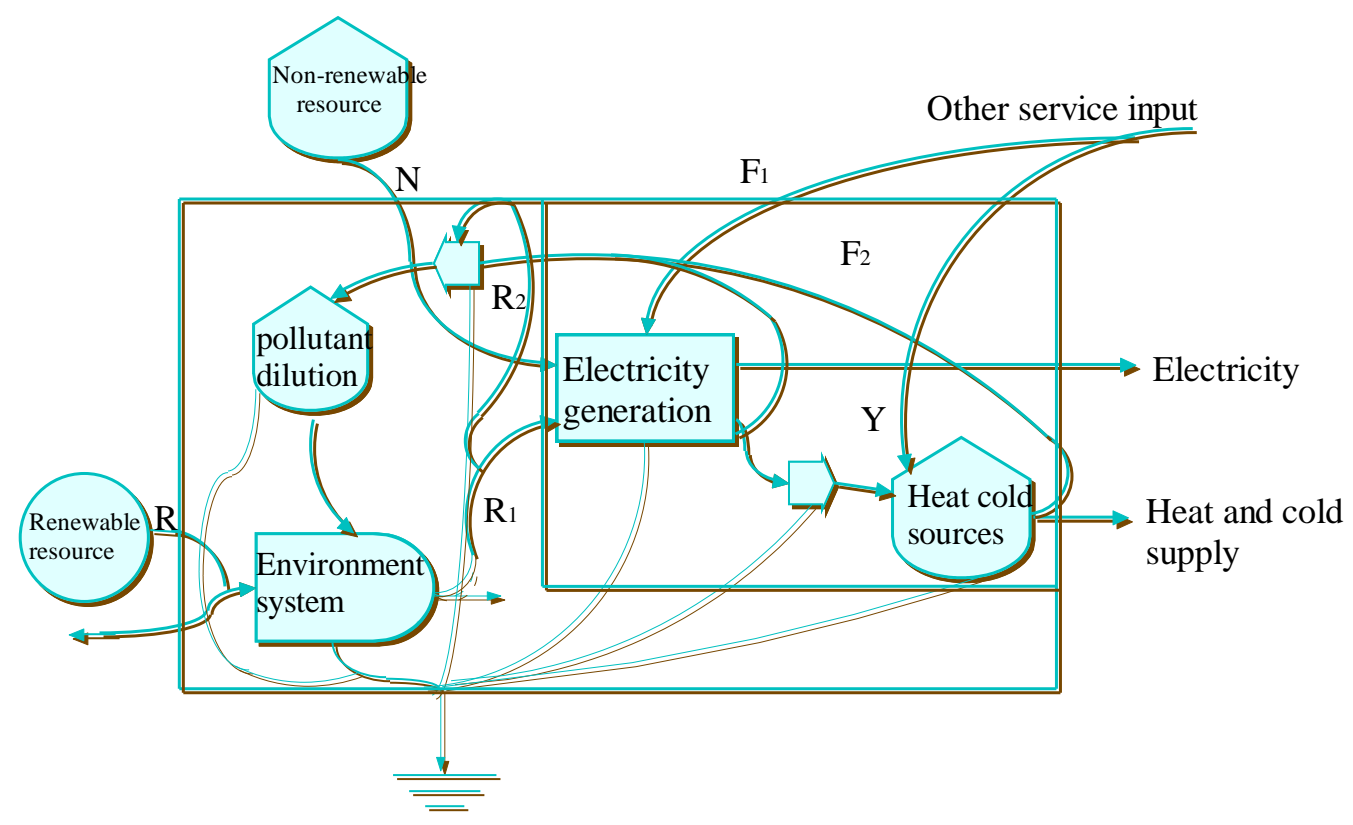

Figure 1: Emergy flow in energy sources for HVAC system 


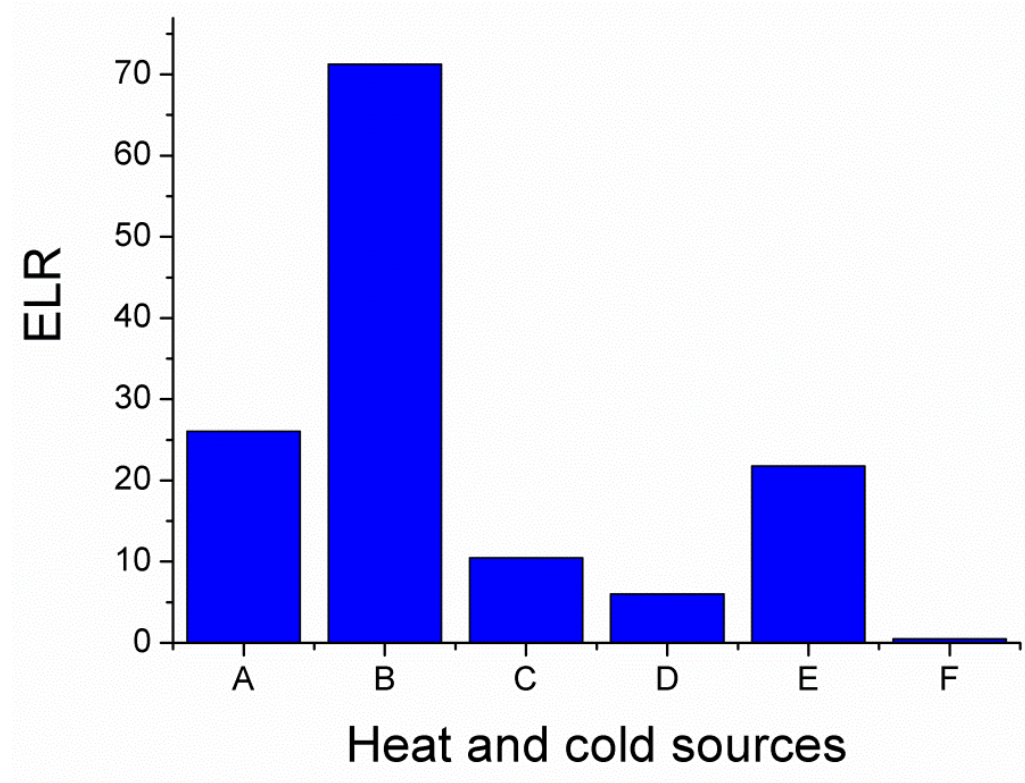

Figure 2: Environmental load ratio of different options 


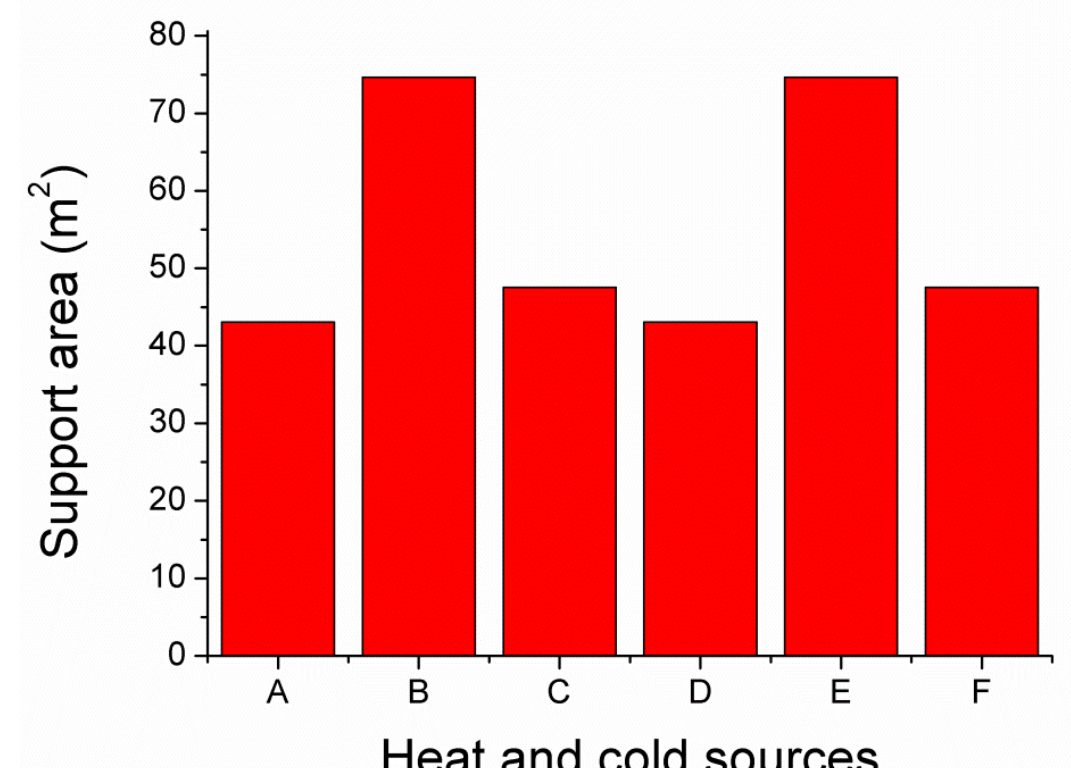

Figure 3. Environmental carrying capacity of anthropogenic heat for different options 